\section{Surface Topology of Chilling Injury of Tomato Fruit}

\author{
Georges T. Dodds ${ }^{1}$ and Pamela M. Ludford ${ }^{2}$ \\ Vegetable Crops Department, Cornell University, Ithaca, NY 14853-0327
}

Additional index words. cold stress, postharvest physiology, Lycopersicon esculentum, Lycopersicon peruivianum, Solanum pennellii

Abstract. Chilling-injury symptoms on the surface of eight cultivars or lines of tomato (Lycopersicon esculentum Mill.) fruit were mapped with respect to subtending locules. Mature-green (MG) fruit were chilled at SC for 10 to 25 days and then ripened to red ripe at 20C. Mature-green fruit showed a major portion of injury over subtending locules and on the stem end. The location of injury corresponded with the regions that were the last to ripen. The injuries of immature-green (IG) fruit treated in a similar manner were different from those of MG fruit both in appearance and in distribution.
Mature-green (MG) tomato fruit stored at nonfreezing temperatures below $12.5 \mathrm{C}$ for extended periods express chilling injury $(\mathrm{CI})$ peratures (Morris, 1982). Symptoms of CI include delayed, partial, or uneven ripening, pitting, and an increased susceptibility to $\mathrm{Al}$ ternaria tenuis and other rots (McColloch and Worthington, 1952). The severity of CI is related directly to the duration of exposure (Autio and Bramlage, 1986; McColloch and Worthington, 1952, 1954; Tomkins, 1963) and inversely to the storage temperature (Abdel-Maksoud et al., 1974; Efiuvwevwere and Thorne, 1988) and to the maturity (mature-green to red ripe) of the fruit when chilled Cultivars show various degrees of tolerance to CI (Abou-Aziz et al., 1974b; GonzalezRamirez et al., 1978; King and Ludford, 1983; Segall et al., 1963). According to qualitative observations, CI tends to occur on the stem end (Furlong, 1946; Rosa, 1926) and in the equatorial region of the fruit (Efiuvwevwere and Thorne, 1988). Hall (1961) observed that fungal infection was located predominantly near the stem and blossom scars of surface-sterilized, chilled tomato fruit. These were also the only portions of surface-sterilized fruit that contained microorganisms (Hall and Mullins, 1965). Hobson (1987) observed that chilling could cause the outer locule walls to remain permanently green. The present study sought to delineate more specifically the distribution of nonfun-

The lines and cultivars used in this study and their characteristics are summarized in

Received for publication 18 Dec. 1989. Vegetable Crops Dept. Paper no. 888. We thank R. Robinson, New York State Agricultural Experiment Station, Geneva, N.Y., and S. Valerio, U.S. Dept. of Agriculture Germplasm Resources, Geneva, for samples of tomato fruit. We also thank B.J. Kurinec for technical assistance. The cost of publishing this paper was defrayed in part by the payment of page charges. Under postal regulations, this paper therefore must be hereby marked aadvertise ment solely to indicate this fact.

${ }^{1}$ Graduate Student in Botany.

${ }^{2}$ Associate Professor of Vegetable Crops. during subsequent ripening at ambient tem(Abou-Aziz et al., 1974b; Furlong, 1946). gal CI symptoms.
Table 1. Chilling tolerance was based on a subjective evaluation of all symptoms of CI. Field-grown MG tomato fruit were handharvested in early September at the Homer C. Thompson Vegetable Research Farm, Freeville, N.Y. (1988); the East Ithaca Vegetable Research Farm, Ithaca, N.Y. (1988, 1989); and the Vegetable Research Farm and U.S. Dept. of Agriculture Germplasm Resources plots at the New York State Agricultural Experiment Station, Geneva (1989). Fruit maturity was determined in the field on the basis of the size of the fruit, its position on the plant, the smoothness of its shoulder, and by cutting open representative fruit and observing locule development. The time of harvest (1330 to $1430 \mathrm{HR}$ ) was chosen as likely to yield fruit with high CI sensitivity (Saltveit and Cabrera, 1987). Fruit were dipped for $3 \mathrm{~min}$ in a 300-ppm chlorine so- lution, placed stem end down on sterilized plastic trays, and chilled in the dark at $5 \mathrm{C}$. Fruit were removed after 10,15 or 16,20 , and 25 days and ripened to red ripe (10 to 12 days) in darkness at 20C.

Chilled and ripened fruit were mapped for CI only when fungal decomposition was minimal and the regions of pitting and/or delayed ripening were clearly distinguishable. In those cultivars that were rapidly overgrown with pathogens, the number of tomatoes available for mapping was limited. The fruit height (ht) and maximum and minimum equatorial diameters ( $\max$ and min, respectively) were measured. The surface area, volume, and surface area : volume ratio of the fruit were calculated based on a sphere with a radius: $\mathrm{r}=(\mathrm{ht}+[(\max +$ $\mathrm{min}) / 2]$ )/4. A surface arc from the center of the stem scar to the blossom scar was measured and divided into 14 equal segments (Fig. 1). The arc and divisions between segments were drawn on the ripe tomato with an indelible marker. An opposite arc was also drawn to maintain the same orientation throughout mapping. Transverse sections at the divisions yielded slices perpendicular to the stem-blossom scar axis (Fig. 1). For each hemisphere, the injury on the epidermal surface of each slice and the area occupied by the subtending locules were plotted onto polar coordinate paper. Each hemisphere of fruit was divided into 35 rings, with five rings per slice (Fig. 1). Due to the curvature of the regions closest to the blossom and stem scars and the plane of section, the locules were generally absent or much reduced. The first 15 or 20 rings were therefore cut as one multi-slice dome and only the injury was mapped (injury-unmapped lo-
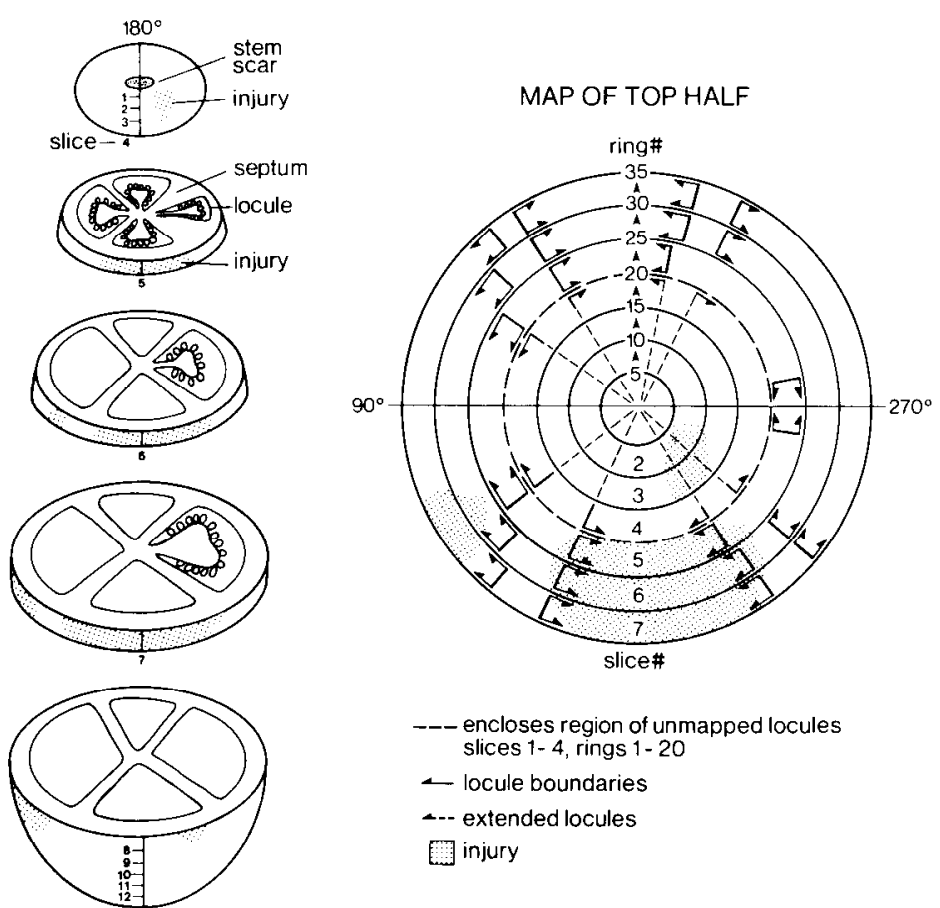

--- encloses region of unmapped locules slices $1-4$, rings 1 - 20

— locule boundaries

-.- extended locules

injury
Fig. 1. Relationship of visual surface injury and locule position of a sliced marked fruit to the mapped injury and locules. 


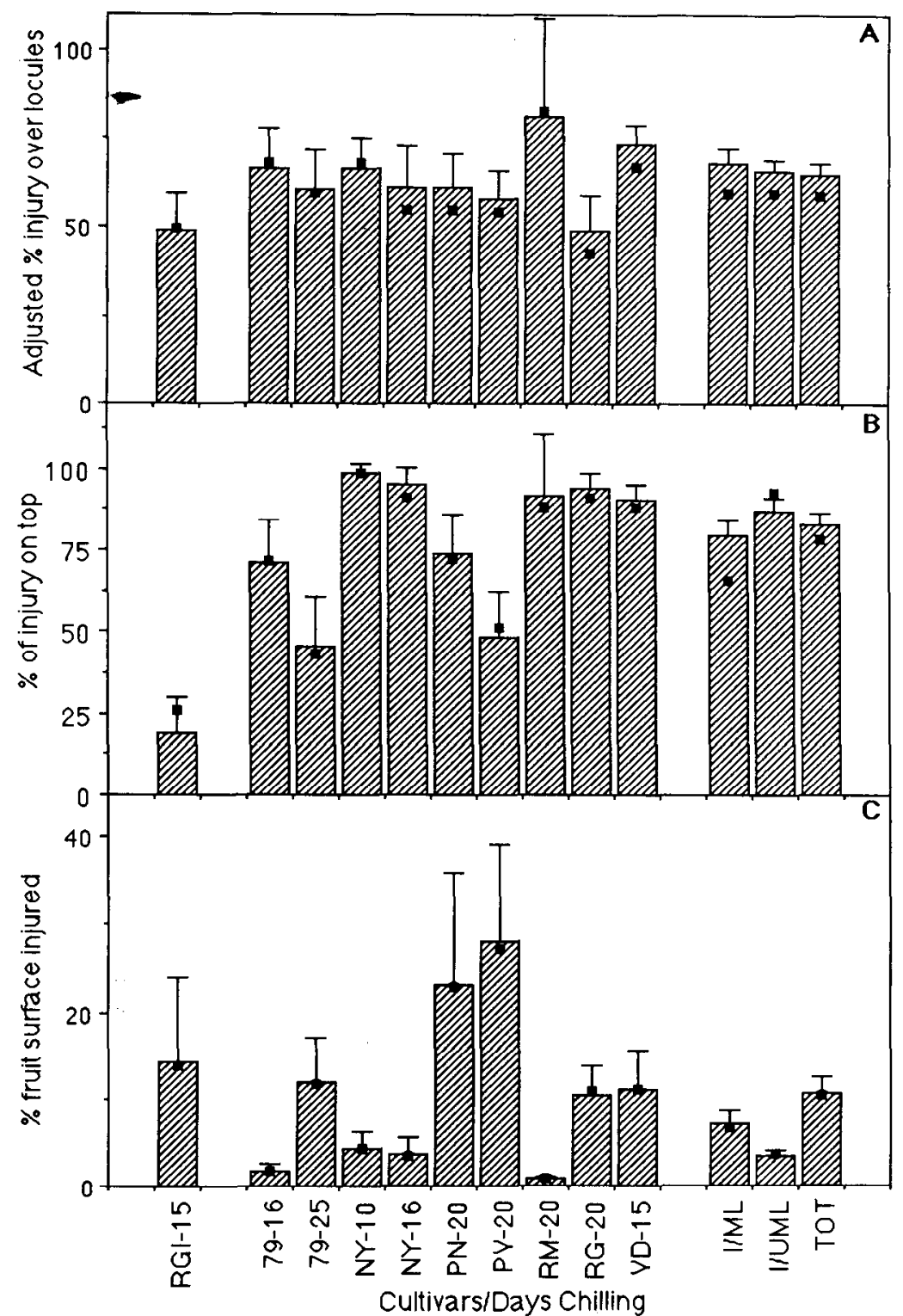

Fig, 2. Distribution and amount of injury on chilled and ripened mature-green (MG) and immaturegreen (IG) fruit. (A) Adjusted percent injury over locules; (B) percent injury on top hemisphere; (C) percent fruit surface injured. Average and error bar representing 95\% confidence interval for the mean are shown. ( ) = Scaled average. Cultivars: NY = MG 'New Yorker'; RG = MG 'Rutgers'; RGI = IG 'Rutgers'; RM = MG 'Roma'; VD = MG 'Vendor', Lines: $\mathrm{PN}=$ L. esculentum x $S$. pennellii (89-106V, 89-107V); PV = L. esculentum x L. peruvianurn (89-77), $79=$ 'New Yorker' $\mathrm{x}$ 'Florida 407' (79-546). All MG cultivars/lines: I/ML = injury located in a region of mapped locules; $\mathrm{I} / \mathrm{UML}=$ injury located in a region of unmapped locules; $\mathrm{TOT}=\mathrm{I} / \mathrm{ML}+\mathrm{I} / \mathrm{UML}$, i.e., total injury.

cules). Injury on the remaining slices of each hemisphere was termed injury-mapped lod e s .

CI was analyzed independently for each location on the fruit and also in combination. The subtending locules would have been evident if the slices of the unmapped locule regions had been taken radially rather than transversely. Therefore, the locule boundaries used in the analysis of the injury-unmapped locule region were obtained by extending inward the locules of the innermost ring in the region of mapped injury. If a locule to be extended inward had a width of $<25 \%$ of that locule in the innermost ring of the next outward slice, then the latter locule dimension was used (Fig. 1). The per- by locules. A scaled average of these quantities was then obtained by recalculating the percentages from their summed components, thus taking into account the relative amounts of injury on each fruit. Distribution of injury over the fruit surface was analyzed using a $x^{2}$ test. The Student's t test with arcsin transformation (Little, 1985) was used for comparison of percentages between cultivars or lines. Correlations were tested using the Spearman Rank Correlation Test. The latter two tests were performed with StatWorks (Version 1.2) from Cricket Software.

For all MG fruit, certain criteria (adjusted percent injury over locules, percent fruit surface injured, percent area subtended by locules, and percent injury area on top half) were analyzed for correlations (Spearman Rank Correlation) between themselves and with additional characteristics (fruit height, maximum and minimum equatorial widths, maximum : minimum ratio, surface area, and surface : volume ratio).

The percentage of injury over locules was positively correlated $(P \leq 0.001)$ with height and surface area of the fruit. The adjusted percentage of area subtended by locules was inversely correlated $(P \leq 0.05)$ with the percentage of area injured on the top half. Thus, the greater the area subtended by locules the more evenly injury was distributed between the top and bottom of the fruit.

A comparison of all MG fruit (Student's $t$ test) with respect to injury-unmapped locules and injury-mapped locules showed a higher adjusted percent injury over locules $(P \leq 0.05)$ for the mapped locule region than for the unmapped locule region (Fig 2A). The larger percent area subtended by locules $(P \leq 0.01)$ of the mapped vs. unmapped locule region is due to the mode of derivation of the locule areas for the unmapped locule areas. The mapped locule region shows a lower percentage of area injured on the top half $(P \leq 0.01)$ than the unmapped locule region (Fig. 2B), largely because, in most cases, there was little or no injury on the unmapped locule region of the lower hemisphere of the fruit. The percent fruit surface injured was greater for the mapped locule regions $(P \leq 0.05)$ than for the unmapped regions (Fig. $2 \mathrm{C}$ ), reflecting the greater overall area of the mapped locule regions.

Days of chilling had no effect on the adjusted percent injury over locules (Fig. 2A) for either 79-546 or 'New Yorker' fruit. Line 79 decreased in percent injury on top $(P \leq$ $0.05)$ with increased days of chilling, whereas 'New Yorker' did not (Fig. 2B). The duration of chilling increased the percent fruit surface injured $(P \leq 0.001)$ for the chillingtolerant 79 fruit but did not affect this characteristic in the case of the chilling-sensitive 'New Yorker' fruit (Fig. 2C). The low percentage of fruit surface injured and lack of response to chilling duration of 'New Yorker' are not inconsistent with its being considered a sensitive cultivar as it does show a great deal more fungal rot than the other cultivars/ lines used.

Chilling-tolerant 16-day chilled 79 fruit and 20-day chilled 'Roma' fruit showed a lower 
Table 1. Cultivars and lines used, their abbreviations, days of chilling at SC, number of fruit sampled, chilling tolerance, fruit type, and surface : volume ratio.

\begin{tabular}{|c|c|c|c|c|c|c|}
\hline $\begin{array}{l}\text { Cultivar } \\
\text { or line }\end{array}$ & $\begin{array}{l}\text { Derivation of line } \\
\text { or cultivar }\end{array}$ & Abbr. & $\begin{array}{l}\text { Days of } \\
\text { chilling }\end{array}$ & $\begin{array}{l}\text { Number } \\
\text { mapped }\end{array}$ & $\begin{array}{l}\text { Chilling } \\
\text { tolerance }\end{array}$ & $\begin{array}{l}\text { Average surface: } \\
\text { volume ratio }\end{array}$ \\
\hline \multirow[t]{2}{*}{ New Yorker } & Cultivar & NY & 10 & 12 & + & 1.16 \\
\hline & & & 16 & 18 & & 1.15 \\
\hline Vendor & Cultivar & VD & 15 & 44 & + & 1.18 \\
\hline Rutgers & Cultivar & RG & 20 & 12 & $t+t$ & 1.11 \\
\hline Roma & Cultivar & RM & 20 & 4 & $++t+$ & 1.22 \\
\hline $89-77$ & $\begin{array}{l}\text { Lycopersicon esculentum L. } \times \\
\text { L. penvianum (L.) Mill. }\end{array}$ & PV & 20 & 8 & $+t$ & 1.53 \\
\hline \multirow{4}{*}{$\begin{array}{l}89-106 \mathrm{~V} \text { and } \\
89-107 \mathrm{~V} \\
79-546\end{array}$} & L. esculentum L. $\mathrm{X}$ & PN & 20 & 5 & ++ & 1.02 \\
\hline & Solanum pennellii Corr. & & & 3 & ++ & \\
\hline & New Yorker $\mathrm{x}$ & 79 & 16 & 14 & ++++ & 1.20 \\
\hline & Florida 407 & & 25 & 10 & & 1.09 \\
\hline Total & & & & 130 & & 1.22 \\
\hline Rutgers & Cultivar & $\mathrm{RGI}^{\mathrm{y}}$ & 15 & 21 & + & 1.31 \\
\hline
\end{tabular}

${ }^{\mathrm{z}}$ Subjective evaluation of tolerance to all forms of CI: $+=$ susceptible, $+++++=$ tolerant.

${ }^{\mathrm{y}}$ Harvested immature green.

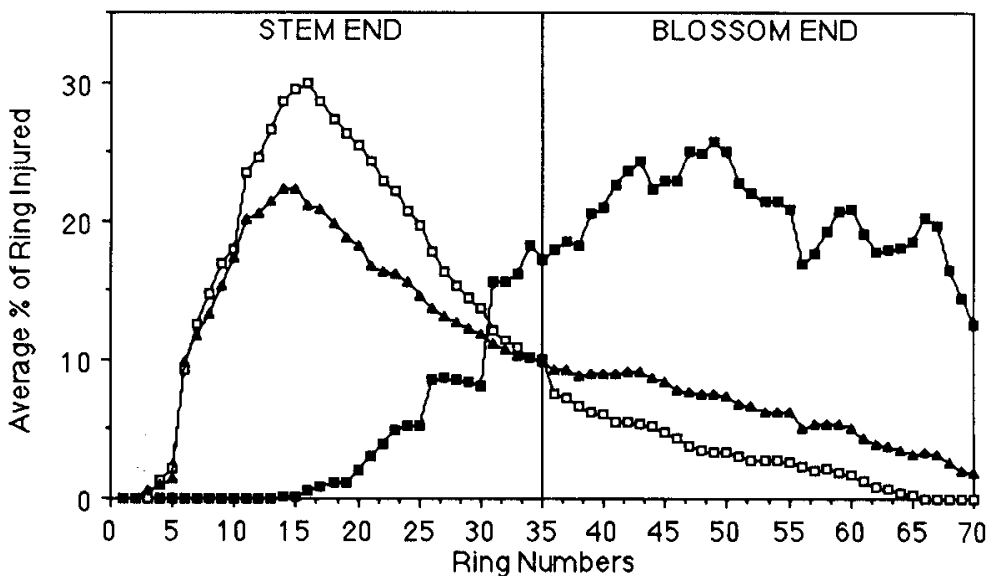

Fig. 3. Distribution of injury on tomato fruit chilled at $5 \mathrm{C}$ and ripened at $20 \mathrm{C}: \mathbf{\Delta}=$ all $\mathrm{MG}$ lines/ cultivars combined; $\square=$ 'Rutgers' MG; $\mathbf{\square}=$ 'Rutgers' IG.

percentage of fruit surface injured $(\mathrm{P} \leq 0.05)$ than all other cultivars/treatments collectively and individually for all but 16-day chilled 'New Yorker'. Overall, the injured fruit of the two most tolerant cultivars/lines (79, 'Roma') showed the least percent fruit surface injured.

Chi-squared tests based on the injury counts per ring (data not shown) revealed that all cultivars or lines individually and collectively differ from an equal distribution of injury between top and bottom $(P \leq 0.001)$ and that they also differ from a random distribution of injury over the entire fruit $(P \leq$ $0.001)$. The distribution of injury for 'Rutgers' and for all cultivar/lines combined (percent of ring injured vs. ring number) is shown in Fig. 3. The CI symptoms were mostly on the top (stem scar) half, and show no concentration in the equatorial region as was described by Efiuvwevwere and Thorne (1988). This predominance of CI on top was observed individually (by cultivar or line) and collectively in MG fruit, except for 16day chilled 79 and 20-day chilled 89-106V, and $89-107 \mathrm{~V}$ (PN, see Table 1) fruit, which had a roughly equal distribution between top and bottom. Thus, the observations of Rosa (1926) and Furlong (1946) were confirmed quantitatively.

The adjusted percent injury over locules
(Fig. 2A) was $>50 \%$ for all cultivars except 'Rutgers'. A paired Student's $t$ test showed the unadjusted percent injury over locules to be greater than the percent surface area subtended by locules for 16-day chilled $79(P$ $\leq 0.05)$, 10-day chilled 'New Yorker' $(P \leq$ $0.01)$, 15-day chilled 'Vendor' $(P \leq 0.001)$, and all MG fruit combined $(P \leq 0.001)$. Thus, we have shown quantitatively that $\mathrm{CI}$ occurred predominantly over locules rather than over septa, confirming the qualitative observations of Hobson (1987).

Some 'Rutgers' fruit were harvested immature green (IG). They were smaller than the MG 'Rutgers' fruit, as can be seen from their surface area : volume ratios (Table 1). Furthermore, their position on the plant, the presence of a ridged shoulder, and the lack of locule gel development in several representative fruit cut in the field confirmed the immature nature of these fruit. While the IG fruit did eventually turn red and soften (25 to 30 days vs. 10 to 12 days for MG), the seeds remained small and the amount of locule gel minimal. Chilling injury in IG fruit differed from that in $M G$ fruit. Immaturegreen fruit showed browning and blistering symptoms during chilling, but generally symptoms did not develop further during the 2.5 to 30 days these fruit required to ripen. A similar appearance and distribution of $\mathrm{CI}$ on IG fruit was observed, but not mapped, in other cultivars (Hayslip, Redpik), in lines (alc/alc, alc/alc 'Rutgers'), and in fruit of unknown cultivars obtained from a local commercial distributor. The percent injury on top for 15-day chilled IG 'Rutgers' fruit (Fig. 2B) was less than that for either 20day chilled MG 'Rutgers' fruit or all MG fruit combined $(P \leq 0.001)$. The injury on IG fruit most commonly was on the bottom hemisphere, whereas it was predominantly on the top hemisphere of MG fruit (Fig. 3). Like 20-day chilled 'Rutgers' MG fruit, 'Rutgers' IG fruit chilled for 15 days showed an adjusted injury over locules (Fig. 2A) of $\approx 50 \%$, lower than all MG fruit combined ( $P$ $\leq 0.05$ ).

Surface color development of MG tomato fruit proceeds from the blossom scar upwards along the areas subtended by septa and finally over those areas subtended by locules. The stem-scar end/over locule regions are the last to ripen. Both color development and injury distribution showed more clearcut differences for top vs. bottom than for over locules vs. over septa. The distinction in color development in over locule vs. over septa was most readily seen in 'Vendor' fruit, but was less evident in other cultivars, such as 'Rutgers'. Similarly, the distribution of injury between these two regions showed more injury over locules for 'Vendor' than for 'Rutgers' fruit $(P \leq 0.001)$. The location of observed CI symptoms predominantly on the top half and over locules, namely the least mature region of the fruit, was consistent with the conclusion of Furlong (1946) that less-mature fruit, within the range from mature-green to red ripe, are more susceptible to $\mathrm{CI}$.

\section{Literature Cited}

Abdel-Maksoud, M.M., A.B. Abou Aziz, A.S. Abdel Kader, and K.A. Abdel-Samie. 1974. Influence of growing season and storage temperature on chilling injury of tomato fruit Egyptian J. Hort. 1:271-274.

Abou-Aziz, A.B., M.M. Abdel-Maksoud, K.A. Abdel-Samie, and A.S. Abdel-Kader. 1974a. Comparative effects of chilling injury on three cultivars of tomato harvested-at "mature-green stage. Gartenbauwissenschaft 39:191-198. 
Abou-Aziz, A.B., M.M. Abdel-Maksoud, K.A. Abdel-Samie, and A.S. Abdel-Kader. 1974b. Effect of picking stage and temperature on quality and ripening of tomato fruits. Gartenbauwissenschaft 39:37-45.

Autio, W.R. and W.J. Bramlage. 1986. Chilling sensitivity of tomato fruit in relation to ripening and senescence. J. Amer. Soc. Hort. Sci. 111:201-204.

Efiuvwevwere, B.J.O. and S.N. Thorne. 1988. Development of chilling injury symptoms in stored tomato fruit (Lycopersicon esculentum Mill.). J. Sci. Food Agr. 44:215-226.

Furlong, C.R. 1946. The storage and ripening of green tomatoes. Agr. J. Min. Agr. Great Britain 53:313-316.

Gonzalez-Ramirez, A., J.R. Hicks, and M.H. Tabacchi. 1978. Chilling sensitivity differences in tomato lines. HortScience 13:390. (Abstr.)

Hall, C.B. 1961. The effect of low storage tem- perature on the color, carotenoid pigments, shelflife and firmness of ripened tomatoes. Proc. Amer. Soc. Hort. Sci. 78:480-487.

Hall, C.B. and J.T. Mullins. 196.5. Cellulase activity in sterile tomatoes. Nature (London) 206:638

Hobson, G.E. 1987. Low-temperature injury and the storage of ripening tomatoes. J. Hort. Sci. 62:55-62.

King, M.M. and P.M. Ludford. 1983. Chilling injury and electrolyte leakage in fruit of different tomato cultivars. J. Amer. Soc. Hort. Sci. 108:74-77.

Little, T.M. 1985. Analysis of percentage and rating scale data. HortSciencc 20:642-644.

McColloch, L.P. and J.T. Worthington. 1952. Low temperature as a factor in the susceptibility of mature-green tomatoes to Alternarin rot. Phytopathology 42:425-427.

McColloch, L.P. and J.T. Worthington. 1954.
Ways to prevent chilling of mature-green tomatoes. Pre-Pack Age 7(6):22-25.

Morris, L.L. 1982. Chilling injury of horticultural crops: An overview. HortSciencc 17:161-162.

Rosa, J.T. 1926. Ripening and storage of tomatoes. Proc. Amer. Soc. Hort. Sci. 23:233-242.

Saltveit, M.E., Jr. and R.M. Cabrera. 1987. Tomato fruit temperature before chilling influences ripening after chilling. HortScicncc 22:452-454.

Scgall, R.H., N.C. Hayslip, and J.M. Walter. 1963. Effect of postharvest temperature on several tomato varieties harvested at the maturegreen stage. Proc. Fla. State Hort. Soc. 76:172177.

Tomkins, R.G. 1963. The effects of temperature, extent of evaporation, and restriction of ventilation on thestorage life of tomatoes. J. Hort. Sci. 38:335-347. 